\title{
GPR, a ground-penetrating radar for the Netlander mission
}

\author{
J. J. Berthelier, ${ }^{1}$ R. Ney, ${ }^{1}$ V. Ciarletti, ${ }^{2}$ A. Reineix, ${ }^{3}$ B. Martinat, ${ }^{2,3}$ M. Hamelin, ${ }^{1}$ \\ F. Costard, ${ }^{4}$ P. Paillou, ${ }^{5}$ C. Duvanaud, ${ }^{6}$ D. Nevejans, ${ }^{7}$ W. Kofman, ${ }^{8}$ J. G. Trotignon, ${ }^{9}$ \\ G. Grandjean, ${ }^{10}$ M. Zamora, ${ }^{11}$ and A. Nagy ${ }^{12}$ \\ Received 13 February 2002; revised 21 June 2002; accepted 3 July 2002; published 8 February 2003.
}

[1] In the coming decade, several missions are planned that will land on the surface of Mars landers or instrumented geophysical stations. Among the scientific objectives of these projects, one of the most important will be to unravel the many unknowns in the geological and hydrological history of the planet. The Netlander mission offers a unique opportunity to explore the interior of Mars, its subsurface, its atmosphere, and its distant environment from four landing sites that will be selected to offer a variety of different geophysical conditions. We have thus proposed to fly on these four landers a groundpenetrating radar (GPR) to explore the geological characteristics of the subsurface and search for water reservoirs down to a depth which may be sufficient to allow a possible detection of liquid water. We provide in this paper a short description of this radar which is based on a new concept to allow a 3-D imaging of the subsurface by determining the range and direction of the underground reflectors. In order to access to deep layers, it will operate at a low frequency of $2 \mathrm{MHz}$. Some results obtained by a numerical modeling of the radar operation in an electromagnetic model of the Martian subsurface are presented in order to illustrate the main capabilities of the radar. In the last section, preliminary results from an initial field test are reported. In addition to its primary goal as a groundpenetrating radar, the GPR will also be operated on Mars as an ionospheric sounder and, in a passive mode, as a HF receiver to measure the radio-electric background. INDEX TERMS: 0644 Electromagnetics: Numerical methods; 0994 Exploration Geophysics: Instruments and techniques; 6225 Planetology: Solar System Objects: Mars; 6297 Planetology: Solar System Objects: Instruments and techniques; 6994 Radio Science: Instruments and techniques; KEYWORDS: Planetology, Mars, Mars subsurface, ground-penetrating radar, electromagnetics

Citation: Berthelier, J. J., et al., GPR, a ground-penetrating radar for the Netlander mission, J. Geophys. Res., 108(E4), 8027, doi:10.1029/2002JE001866, 2003.

\section{Introduction}

[2] Among the missions which are presently planned to be flown to Mars during the next decade, a number of

\footnotetext{
${ }^{1}$ Centre d'Etude des Environnements Terrestre et Planétaires/IPSL, Saint-Maur, France.

${ }^{2}$ Centre d'Etude des Environnements Terrestre et Planétaires/IPSL, Velizy, France.

${ }^{3}$ Institut de Recherche en Communications Optiques et Microondes, Universitéde Limoges, Limoges, France.

${ }^{4}$ Orsay-Terre, UniversitéParis-Sud, Orsay, France.

${ }^{5}$ Observatoire Astronomique de Bordeaux, Floirac, France.

${ }^{6}$ LAII, Universitéde Poitiers, IUT, Angoulême, France.

${ }^{7}$ BIRA-Institut d'Aéronomie Spatiale de Belgique, Brussels, Belgium.

${ }^{8}$ Laboratoire de Planétologie de Grenoble, Grenoble, France.

${ }^{9}$ Laboratoire de Physique et Chimie de l'Environnement, Orléans la Source, France.

${ }^{10}$ Bureau de Recherches Géologiques et Minières, Orléans, France.

${ }^{11}$ Institut de Physique de Globe de Paris, Paris, France.

${ }^{12}$ College of Engineering, University of Michigan, Ann Arbor, Michigan, USA.
}

Copyright 2003 by the American Geophysical Union. 0148-0227/03/2002JE001866 investigations relate to the exploration of the surface and sub-surface of the planet. Getting initial observations of the morphology and structure of the underground at depths of the order of a kilometer or more appears of prime interest for a number of reasons. Accessing the geological features which are present in the subsurface will allow us to improve our understanding of the processes which have been active during the formation and evolution of the planet. In particular, it will be extremely interesting to relate them to the different surface features which have been discovered through the initial observations of the Viking spacecraft and have been much better documented in the recent years due to the improved resolution and coverage provided by the MGS camera [Malin and Edgett, 2000]. As an example, it would be of interest to get subsurface stratigraphic data in outwash plains where sedimentation is thought to have occurred over significant depths [Costard and Kargel, 1995], leaving probably layers with different lithologies. Tectonic details and faults have also been detected in a number of places and probing the subsurface in regions where wrinkle ridges are commonly found like Lunae Planum would provide information to test the validity of the initial interpretations [Thomas and Masson, 1995; 
Mangold et al., 1998]. Lava layers from volcanic flows, possibly overlapping with sedimentary layers, are also one of the most interesting targets for Martian geologists. Nevertheless, since water on Mars is the central question on which are focused most of the coming exploratory missions, the search for water reservoirs, either in the form of ground ice or of liquid water, is without any doubt the major objective of all experiments that are related to subsurface investigation. Even initial observations of the hydrology of the subsurface would certainly prove to be essential by providing clues to the most crucial problem of the evolution of the climate and atmosphere of Mars.

[3] During the recent years, a number of studies have led to the idea that, over geological times, the climate of the planet has evolved from a relatively wet and warm climate with a strong hydrological cycle including precipitations and the existence of oceans [Haberle, 1998; Craddock and Maxwell, 1993; Baker et al., 1991] to the presently observed state of a very tenuous and dry atmosphere. The valley networks, mainly found in the old cratered upland, as well as the presence of runoff and outflow channels [Carr, 2001; Baker, 2001], seem to indicate that a stable water layer existed on the surface more than 3 billions years ago and that it persisted in the regolith throughout most of the Martian history. Several models have been tested to reproduce a greenhouse effect which would account for such a warm and wet climate [Sagan and Chyba, 1997; Forget and Pierrehumbert, 1997]. From these and other studies, it is thought that the Martian climate evolved through a periglacial phase from initial Earth-like conditions, with water present on the surface in large quantities, to the presently observed state of a very tenuous and dry atmosphere. Several authors have presented models that account for the escape of volatiles and their subsequent loss to space through various chemical or physical processes in the upper atmosphere, including in particular the sputtering of atmospheric constituents by energetic ions from the solar wind [Luhmann et al., 1992; Hodges, 2002]. The efficiency of these processes, considerably enhanced during the early phase of the Solar System with a fast solar wind, may explain the erosion of the atmosphere over geologic times. Simultaneously, and as it happened in regions with a periglacial climate on the Earth, a large quantity of water is thought to have gone within the Martian regolith by infiltration and remained stored there under the form of ground ice or, even, liquid water.

[4] It is thus generally agreed that, below a dry layer, a large quantity of volatiles still resides within the Martian subsurface as clay minerals, underground ice, and, possibly at some depth, liquid water. Several well known surface features such as the rampart craters formed by meteoritic impacts [Costard, 1989; Squyres et al., 1992; Barlow et al., 2000] have been used to evaluate the distribution in-depth of the ground ice reservoirs over the different geological regions of the planet. This distribution is characterized by a latitudinal variation which relates to the corresponding variations of the surface temperature: the top of the ground ice layer is found at depths of the order of a few hundreds of meters in equatorial regions and it is at much smaller depths at mid to high latitudes where it can be stable at depths of a few tens of meters in Acidalia Planitia or Utopia Planitia [Costard and Kargel, 1995] and even at ground levels since the soil temperature is permanently below the freezing point poleward of $40^{\circ}$. Such values agree quite well with theoretical estimates of the distribution of volatiles within the crust [Squyres et al., 1992; Clifford, 1993]. Model estimates of the permafrost thickness range from 1 to $3 \mathrm{~km}$ in equatorial regions to 3 to $7 \mathrm{~km}$ at high latitudes [Fanale et al., 1986]. It is expected that, under ground ice, liquid water can exist, at least at low latitudes depending on the geothermal heat flow. The depth of the transition to liquid water can be reduced significantly by pressure and solute effects. New observations from the MGS camera have been reported [Malin and Edgett, 2000; Mellon and Phillips, 2001] showing the existence of recent surface runoff on Mars. Such features have been attributed by these authors to erosion by a running fluid and water, that could be formed by groundwater seepage from an underground aquifer, is a likely candidate, although liquid $\mathrm{CO}_{2}$ has been advocated by Hoffman [2000]. More recently, Costard et al. [2002] have proposed that these landforms may result from the melting of water ice in the top few meters of the Martian subsurface due to variations of the obliquity of Mars. The existences of thermokarst [Mustard et al., 2001], pattern ground [Mangold and Allemand, 2001], and small polygons [Siebert and Kargel, 2001] are geomorphologic evidence for the presence of volatile materials during very recent periods of time [Masson et al., 2001].

\section{Objectives and Concept of the GPR on the Netlander Mission}

[5] The general objectives of the Netlander mission which will deploy the first Geophysical Network on Mars have been described by Counil et al. [2001]. They relate to a variety of scientific subjects which are mostly interdisciplinary and can be often tackled by means of several of the experiments that are included in the payload. They cover the deep interior of the planet, the subsurface and surface, the dynamics of the atmosphere and its interaction with the surface, and the more distant ionized environment of the planet. This mission, with its 4 landers, offers a unique opportunity to explore the Martian subsurface in 4 different locations which can be chosen to represent the most interesting samples of Martian sites. In particular, among the criteria which will be taken into account to select the landing areas, definite attention will be given to those that are related to the subsurface structure and the possible existence of water reservoirs at moderate depths as can be predicted by present-day models. On the Earth, several techniques are available to explore the structure and nature of the subsurface. They include the well-developed seismic methods and the radio-electric techniques, in the form of either passive electromagnetic measurements or active sounding by ground-penetrating radar. In planetary exploration, and in particular in the case of the rather small landers of the Netlander mission, the extremely severe constraints on mass, power, instrument deployment and operation make at the moment the ground-penetrating radar practically the only suitable technique. Originally developed in the early seventies for prospection and geological studies [Annan and Davis, 1976; Arcone, 1981; Wright et al., 1990] it has attracted a large interest also in many more applied usages. We have therefore proposed to fly on the landers a GPR to investigate the geological structures of 
the subsurface and possibly detect the presence of water reservoirs either in the form of ground ice or, even, of liquid water.

[6] These objectives can be met if the range of penetration of the radar is sufficient compared to the anticipated depth of the ice and water reservoirs. According to the papers cited in the previous section, model evaluations range from a minimum depth of $100 \mathrm{~m}$ for the permafrost roof at low latitudes to 2 to $3 \mathrm{~km}$ for the liquid water layer near the equator. A series of measurements of the electromagnetic properties (electrical permittivity, magnetic permeability) of various volcanic and sedimentary materials which are thought to be fairly good analogs of the expected Martian materials have been reported recently by Heggy et al. [2002]. From these results, we were led to select a low frequency of operation in the $\mathrm{MHz}$ range which allows for a sufficient penetration depth as will be shown in section 4 . Moreover, at such a low frequency, the effect of interface roughness and buried objects are less effective to dampen the waves through diffusion than at the higher frequencies of tens or hundreds of $\mathrm{MHz}$ which are generally used by ground-penetrating radars. However, the most challenging difficulty in operating a ground-penetrating radar on the landers relates to the fact that these landers will stay in fixed locations. On the contrary, the classical way to operate a ground-penetrating radar consists in moving the radar over the ground of interest. From a set of measurements that are acquired over a network of different locations, and using signal analysis techniques similar to those of synthetic aperture radars, inversion algorithms [e.g., Habashy and Mittra, 1987] can provide the 3-D structure of the underground reflectors. In the case of the proposed instrument on Netlander which must operate as a true motionless monostatic radar, it has therefore been necessary to develop a new concept of ground-penetrating radar allowing us to determine not only the distance of the reflectors but also their direction. Determining the direction of propagation of electromagnetic waves has been the subject of a number of studies in the last two decades, especially in the case of satellite measurements of ionospheric and magnetospheric plasma waves. Several methods have been developed from the simple case with a few dominant plane waves [Means, 1972; Samson, 1977] to the more complex case of a continuous wave normal distribution function [Lefeuvre and Delannoy, 1979; Lefeuvre et al., 1981]. Such an analysis was performed for example on data from the low-altitude AUREOL-3 spacecraft by Berthelier et al. [1982] and Lefeuvre et al. [1992]. Depending on the signal over noise ratio and the observation time, accuracies of a few degrees to about $10^{\circ}-15^{\circ}$ in worst cases have been typically estimated. The above mentioned methods are based on the simultaneous analysis of the electric and magnetic components of the waves, necessitating for example 3 components in the simplest case of a plane polarized wave and up to the complete set of 6 components in the most general case. In order to supply the necessary data, the GPR was therefore designed to measure 2 electric and 3 magnetic components of the reflected waves returning to the lander from which a subsequent signal analysis performed on ground will determine the wave propagation vectors. The GPR will thus allow us to obtain both the distance and direction of the underground reflectors, pro- viding a 3-D image of the subsurface in the vicinity of each lander.

[7] The permittivity of the superficial layers of the subsurface is a needed parameter to properly ascertain the actual characteristics of the GPR electric antennas as well as the results of the analysis of the reflected wave propagation vectors. We foresee adding to the radar itself an electronic circuit which will allow us to measure an integrated value of the permittivity over the superficial first meters of the soil. The principle of this measurement is to determine the HF impedance between one of the transmitting electric antennas and a small receiving electrode laid on the ground at about $1.5 \mathrm{~m}$ from the lander structure. The electrode will be the external metallic housing of the magnetometer sensor which is positioned at the end of a boom extending from the solar panels. The transfer function between the transmitting electric antenna and the receiving electrode depends on the permittivity of the soil and can be determined from a precise electrostatic model of the complete electrical system including the electric antennas, lander structure and receiving electrode.

[8] In the following section a more detailed description of the GPR will be given, presenting the rationale for the definition of the radar parameters. For reasons exposed thereafter a frequency of operation of $2 \mathrm{MHz}$ has been selected. In view of the great interest to study the ionized environment of Mars and its dynamical interaction with the solar wind, we have investigated the capability of the GPR to be operated as an ionospheric sounder to probe the lower ionosphere of the planet. Model calculation, supported by preliminary results from the first field test of the GPR, have shown that it has enough sensitivity to provide ionospheric profiles above an altitude of about $90 \mathrm{~km}$ up to the maximum of ionization near $135 \mathrm{~km}$. This forms the second objective of the GPR which will thus be operated in conjunction with the NEIGE experiment [Hoolst et al., 2000] on board Netlander to explore the ionosphere of Mars.

[9] A last objective of the experiment is devoted to the measurement of the radio-electric background at HF frequencies with the GPR simply working as a passive receiver. During dust storms, dust particles impacting the surface get electrically charged and very large electric fields can build up eventually resulting in electrical breakdowns [Melnik and Parrot, 1998; Farrell et al., 1999]. Such electrical discharges, quite similar to those occurring in terrestrial thunderstorms, should give rise to intense electromagnetic emissions covering a wide frequency range. In its passive mode, the GPR will detect these radio-electric emissions in the frequency band of the receiver from $\sim 0.8 \mathrm{MHz}$ to about 3.5 MHz. Together with ARES, the electric field experiment on Netlander [Berthelier et al., 2000] which will perform electromagnetic wave measurements in the ELF/VLF range, the GPR will thus contribute to a detailed study of the electrical phenomena associated with the major perturbations of the lower atmosphere of Mars, the large scale dust storms. In this mode of operation, and in the absence of atmospheric events, the GPR will also act as a riometer. It will provide an integrated measurement of the daily variation of the ionospheric absorption of the galactic electromagnetic noise and, more interestingly, of its abnormal changes in response to external perturbations such as solar proton events. 


\section{Description of the Instrument and Its Modes of Operation}

[10] In accordance with the concept described in the above section, the GPR has been basically designed to allow the measurement of the electric and magnetic components of the received wave field. A brief overview of the instrument design is given in the following and a more detailed technical description will be the subject of a forthcoming publication [Ney et al., 2002].

[11] As pointed out by Means [1972], the determination of the propagation vectors of returning waves is easier for simple wave fields with discrete waves that are plane polarized and in such a case it can be performed even with a reduced number of electric or magnetic components. We are well aware that the reflection processes on the interfaces or on discrete reflectors such as boulders may well disturb the polarization of the reflected waves [Ulaby et al., 1986; Ogilvy, 1991] but, nevertheless, it is evidently of interest to provide the radar with the capability to transmit plane polarized waves. In addition, being able to transmit linearly polarized waves and vary their polarization will also bring observations of significant interest since the characteristics of the reflected waves are related to the physical and electromagnetic properties of the reflectors. They can also be used to discriminate between various reflectors and detect a specific signature linked to the presence of water. To this aim, a set of three electric antennas with length of 35 $\mathrm{m}$, stored in their deployment device on the flank of the lander body, will be deployed and laid on the ground in a symmetrical pattern dictated by the geometry of the 5 solar panels of the lander (Figure 1). There is one central antenna and two others at an angle of $144^{\circ}$ on each side of the first one. As will be shown in section 4, applying variable phase shifts between the signals fed to the 3 antennas also allows us to modify the global radiation pattern of the electric antennas. Energy can thus be radiated in various directions, resulting in a beam steering capability for the GPR. The antennas are broadband resistively damped quarter-wave monopoles [Wu and King, 1965] similar to those widely used in high-frequency impulse radars [Kanda, 1978; Degauque and Thery, 1986]. At the expense of some loss of efficiency, the damped monopoles reduce the ringing effects detrimental to observations at short distances. The electric antennas will be made of thin Kapton ribbons with a variable resistive metallic layer deposited under vacuum. In order to simplify the electronics and also to save power, only a single antenna will be powered at a time during an elementary mode of operation. The others will be switched on in sequence during the 2 following modes in order to have a complete pattern of transmitted polarization. All processes involved in the underground propagation and reflection processes are linear and the electronic circuits will be carefully set-up to provide the required linearity. Under such conditions, signal synthesis of the data received on the Earth will allow us to reproduce transmitted waves with variable polarization characteristics, in particular a vertically propagating plane polarized wave.

[12] Owing to the very tight constraints of mass which are imposed on the Netlander mission, we have been led to use only one magnetic antenna and to manage in such a way that it can be positioned along three mutually orthogonal directions. This is achieved by installing this antenna on the PANCAM camera which is located at the end of a $1 \mathrm{~m}$ long vertically deployed boom and can be rotated over a complete $360^{\circ}$ to have a complete viewing of the landscape. The antenna is mounted at $54.7^{\circ}$ with respect to the vertical axis and for three azimuth angles of the camera evenly spaced by $120^{\circ}$, the corresponding directions of the magnetic antenna are mutually orthogonal.

[13] The electronics is entirely located inside the lander and, as evidenced by the block diagram displayed in Figure 2 , consists in two main parts, respectively the digital and analog circuits. The digital part is organized around an FPGA which (i) drives a Direct Digital Synthesis (DDS) component used to generate the waveform to be transmitted and (ii) ensures the sampling and analog to digital conversion of the received signals. Among others, this numerically controlled transmission technique provides two major advantages. It offers first a very convenient and versatile way to select the desired frequencies and waveforms of the transmitted signals. In addition, it allows us to sample the received signal at times corresponding to perfectly fixed phase lags compared to the transmitted signal, a property which is essential for measurements which require coherent integration over very long times. The analog circuits are the transmitter filters and amplifiers, the variable gain receiver and the various switches. The transmitter amplifier delivers a nominal power of $10 \mathrm{~W}$ to the antenna. The sensitivity of the electric antennas and their receiver is presently estimated to be better than $5 \mathrm{nV} /(\mathrm{Hz})^{1 / 2}$ for a $3.10^{4} \mathrm{~K}$ galactic noise temperature and the measured sensitivity of the magnetic antenna is $\sim 5.10^{-15} \mathrm{~T} /(\mathrm{Hz})^{1 / 2}$.

[14] We plan to use bi-phase transmission with alternate opposite polarities and have two different types of pulses: short $1 \mu$ s pulses, for short range measurements, and long $10 \mu \mathrm{s}$ BPSK coded pulses for deep sounding. In addition coherent integration will be performed directly in the GPR electronics by the FPGA. It has been shown previously [Berthelier et al., 2000] that the sensitivity required to detect the liquid water interface at $2500 \mathrm{~m}$, as modeled in numerical simulations presented in the next section, calls for a maximum of $2^{16}$ coherent additions for the electric antennas and $2^{24}$ for the magnetic antennas owing to their intrinsic lower sensitivity. The GPR will be operated in several different operational modes dedicated to the specific scientific objectives. These will be the "ground-penetrating radar" mode proper to investigate the subsurface, the "ionospheric" mode to probe the lower ionosphere, the "radio-electric background" mode to study electrical discharges in the atmosphere and perform ionospheric absorption measurements, and the "permittivity probe" mode to determine the permittivity of the superficial soil.

\section{Summary of Results from a Numerical Simulation}

[15] In order to evaluate the GPR performances a considerable effort has been devoted to the numerical simulation of its operation. To this aim we have built a simple model of the electromagnetic characteristics of the Martian subsurface which reproduces the main features that are expected by Martian geologists. An FDTD method has been used to describe the wave propagation and diffusion 


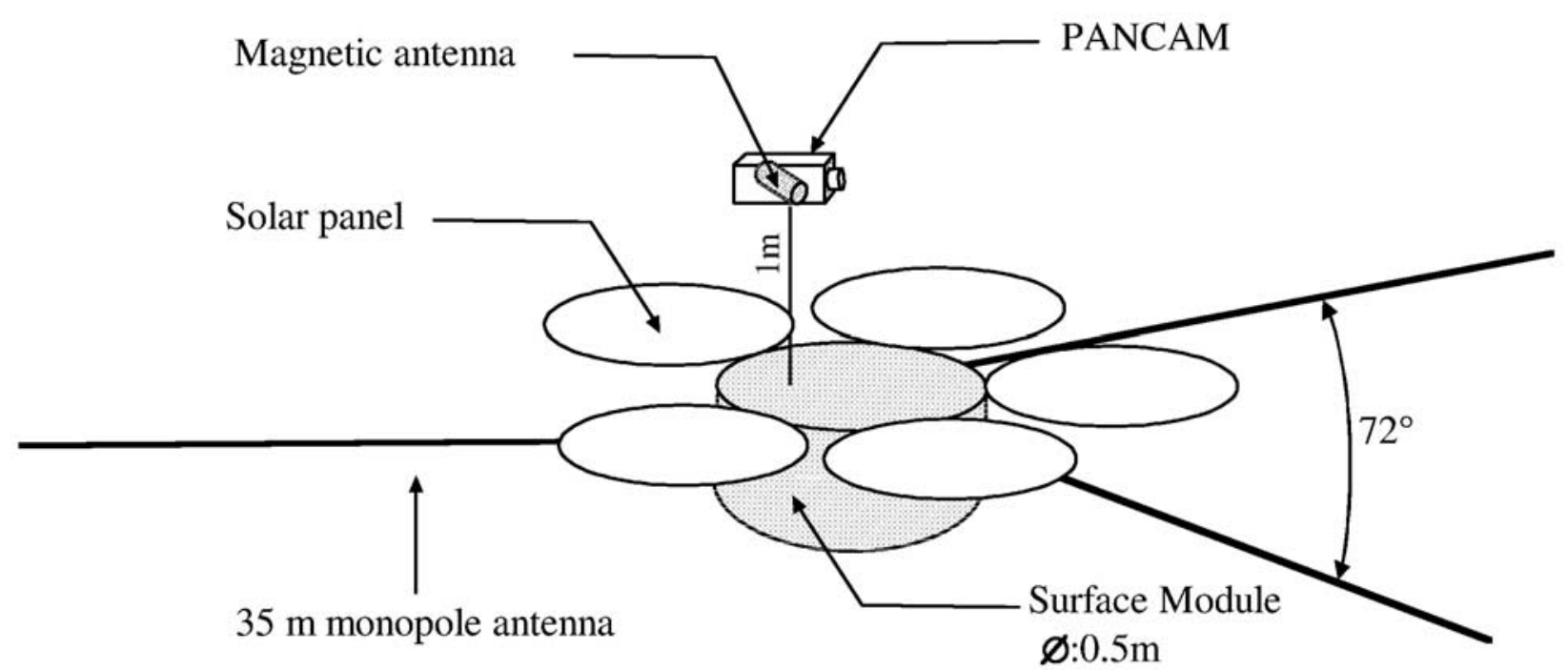

Figure 1. A schematic view of the lander structure showing the deployed solar panels, the three electric antennas laid on the ground and the magnetic antenna fixed on the camera.

[Martinat, 2001] and the numerical algorithms have been adapted from a more general code already developed by IRCOM at the University of Limoges. This numerical scheme takes fully into account the actual characteristics of the whole instrument by considering as the input the voltage waveform sent from the transmitter amplifier to the antenna and as the output the current sent by the antenna to the receiver. A more detailed description of this method together with some results of an initial work on signal analysis are presented in a companion paper [Ciarletti et al., 2003]. We shall restrict here to only the most important results which help in determining the basic performances of the GPR.

[16] In the present state of knowledge, the Martian underground can be roughly divided into three main parts [Clifford, 1993]:

- a first zone consisting of sedimentary deposits and, in some regions, layers of lava from volcanic flows which has been remodeled at least partially by impact processes. The uppermost part of this zone consists in a dry material with negligible water content, while deeper layers may already contain ground ice. In our model we took a total thickness of $400 \mathrm{~m}$ for this part with a sedimentary layer partially filled with ground ice below $150 \mathrm{~m}$.

- a second zone consisting of the fractured, porous megaregolith that can extend to considerable depths with the porosity decreasing with depth. This zone represents the most probable water reservoir with ice in the upper layers and possibly liquid water below some level, the depth of which mainly depends on the local geothermal gradient. In our model, the depth of the melting level of water has been taken equal to $2500 \mathrm{~m}$. This value is consistent with numbers already given in the first section for landing sites in equatorial or low-latitude regions.

- the last zone is the solid basaltic basement either unfractured or with a vanishing porosity due to physical and chemical compaction [Binder and Lange, 1980; Clifford, 1981].

[17] The electromagnetic characteristics of the various layers were adapted from available laboratory measurements, in particular those made on Martian like materials [Heggy et al., 2001]. Figure 3 displays a schematic view of the subsurface model together with the average values of the relative electric permittivity $(\varepsilon)$ and loss tangent $(\operatorname{tg} \delta)$. Initial values, on the left side, have been used for all the simulations reported here and those of Ciarletti et al. [2003]. Revised values, on the right side and taken from Heggy et al. [2002], were used only to evaluate the modification which they brought to the radar power budget reported in Table 1.

[18] This model was first used to evaluate the strength of the echoes associated with the partial reflection of transmitted waves at each interface. Resulting attenuation of the received signal compared to the transmitted signal are displayed in Table 1 for both the initial values of the electromagnetic parameters and the revised ones. They have been calculated for dipolar electric antennas. As can be seen, differences are rather small, well within the uncertainties of the model. Waves reflected at the ground ice-liquid water interface, located in our model at a depth of $2500 \mathrm{~m}$, are attenuated by about $180 \mathrm{~dB}$, a number which is within the range of the anticipated sensitivity of the GPR electric antenna receiver for $2^{16}$ coherent integrations.

[19] The radiation pattern of the electric monopole antennas has been numerically determined and is presented in Figure 4 in the $\mathrm{E}$ and $\mathrm{H}$ planes. The validity of the numerical simulation was checked by comparing results obtained in the case of dipolar electric antennas with the same length and resistance pattern to results published previously for dipolar geometries [e.g., Engheta and Papas, 1982; Arcone, 1995]. Due to the quite large value of the electric permittivity of the upper layer of the soil, most of 


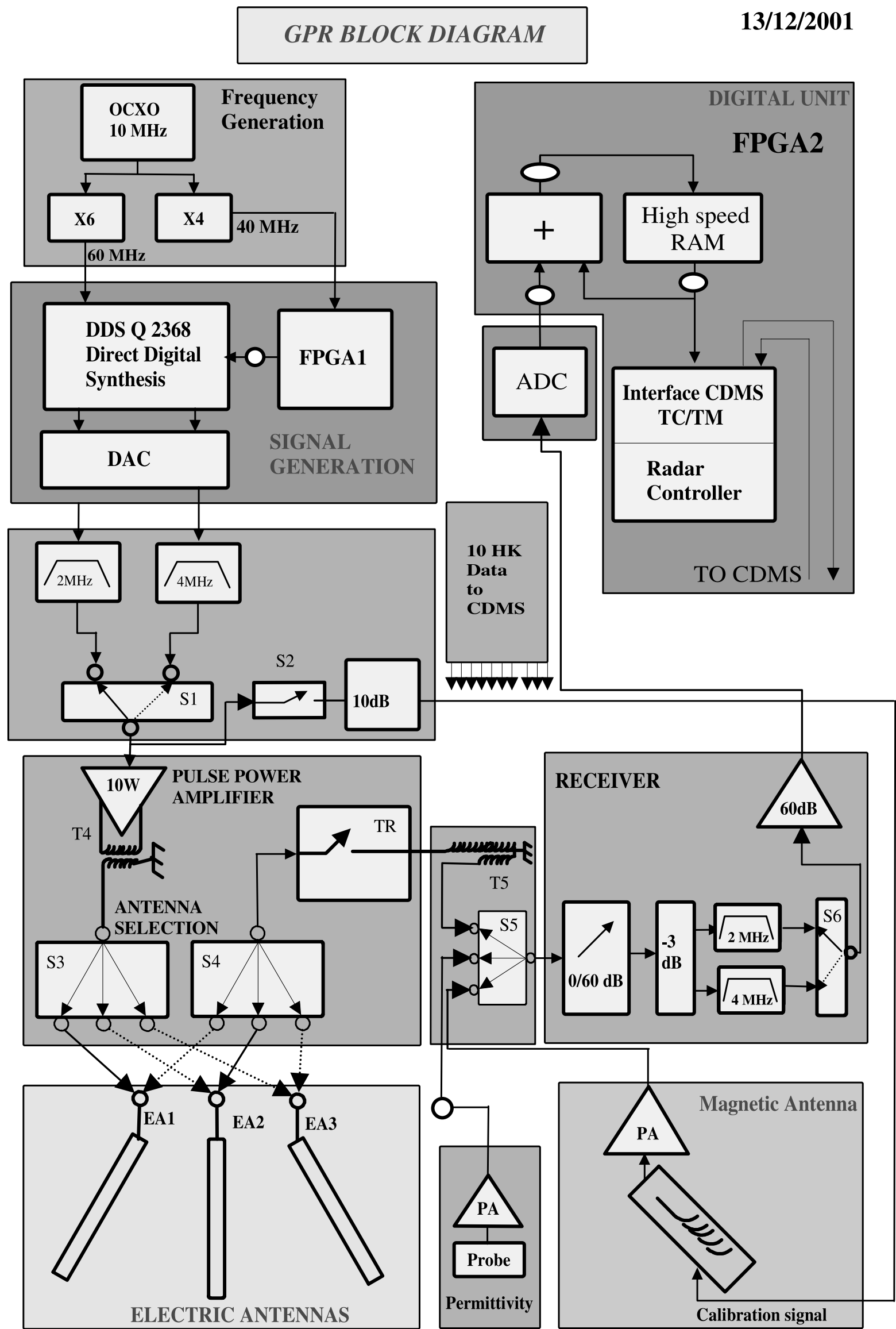

Figure 2. Electronic block diagram of the GPR 


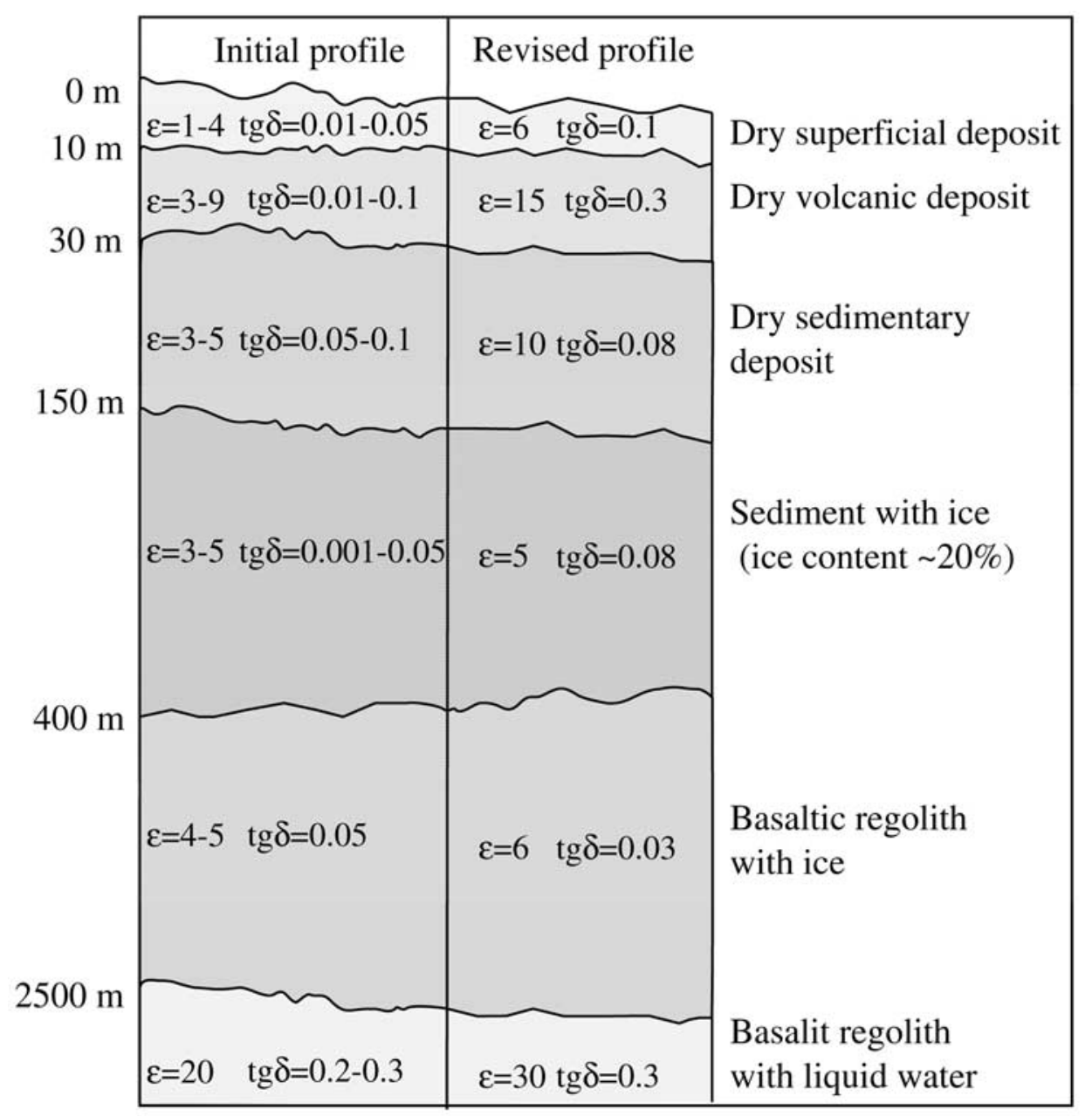

Figure 3. The model of the layered Martian subsurface which was used for numerical simulation of the GPR operation. Values of the electromagnetic parameters in each layer are indicated. Initial values were used for all simulations reported in this paper and by Ciarletti et al. [2003]. Revised values, indicated on the right and taken from Heggy et al. [2002], were only used to obtain results of Table 1.

the energy is radiated toward the ground. The actual radiation pattern of the monopole electric antennas remains quite close to that of an interfacial dipole in similar conditions. The main difference which appears in the Eplane is an asymmetry between the side lobes and a global tilt of the three lobes along the direction of the antenna. The far-field region, defined as the region where the radiated wave field varies approximately as the inverse of the distance to the radar, begins at a distance of $150 \mathrm{~m}$. In order to illustrate the beam steering capability of the radar obtained by varying the phases between the signal fed to the 3 electric antennas, we have simulated two different cases, one with all signals in phase, the second one with a $120^{\circ}$ phase shift on two antennas. The power of the transmitted waves incident on the interface at $400 \mathrm{~m}$ has been calculated and is shown in Figure 5. In the second case the maximum of "illumination" is displaced by about $100 \mathrm{~m}$ and, due to the associated asymmetry of the radiation pattern, the radar gets access to a zone located more than $200 \mathrm{~m}$ farther along the same direction.

[20] A nonnegligible fraction of the energy, about $10 \%$, is radiated upwards which allows the GPR to operate as an ionospheric sounder to probe the lower ionosphere at least during daytime when the electron density at the peak of ionization near $135 \mathrm{~km}$ is greater than $\sim 2 \mathrm{MHz}$. Using models of the electron density profiles in the lower ionosphere of Mars [Whitten et al., 1971; Winchester and Rees, 1995], the absorption of waves reflected from the ionosphere have been calculated for the frequency range of interest. The results of this study have shown that above about 2 to $2.5 \mathrm{MHz}$, the sensitivity of the GPR should be large enough to detect the reflected waves.

[21] To end this section we present results from an initial simulation of the radar operation and of the associated

Table 1. Attenuation of the Detected Echoes With Respect to the Emitted Signal $^{\mathrm{a}}$

\begin{tabular}{rcccc}
\hline & $\begin{array}{c}\text { Min } \varepsilon \\
\text { and } \operatorname{tg} \delta\end{array}$ & $\begin{array}{c}\text { Mean } \varepsilon \\
\text { and } \operatorname{tg} \delta\end{array}$ & $\begin{array}{c}\text { Max } \varepsilon \\
\text { and tg } \delta\end{array}$ & $\begin{array}{c}\text { Revised } \varepsilon \\
\text { and tg } \delta\end{array}$ \\
\hline $150 \mathrm{~m}$ & $-57 \mathrm{~dB}$ & $-68 \mathrm{~dB}$ & $-70 \mathrm{~dB}$ & $-73 \mathrm{~dB}$ \\
$400 \mathrm{~m}$ & $-88 \mathrm{~dB}$ & $-90 \mathrm{~dB}$ & $-94 \mathrm{~dB}$ & $-115 \mathrm{~dB}$ \\
$2500 \mathrm{~m}$ & $-153 \mathrm{~dB}$ & $-182 \mathrm{~dB}$ & $-201 \mathrm{~dB}$ & $-172 \mathrm{~dB}$ \\
\hline
\end{tabular}

${ }^{\mathrm{a}}$ Attenuation measured in $\mathrm{dB}$. 

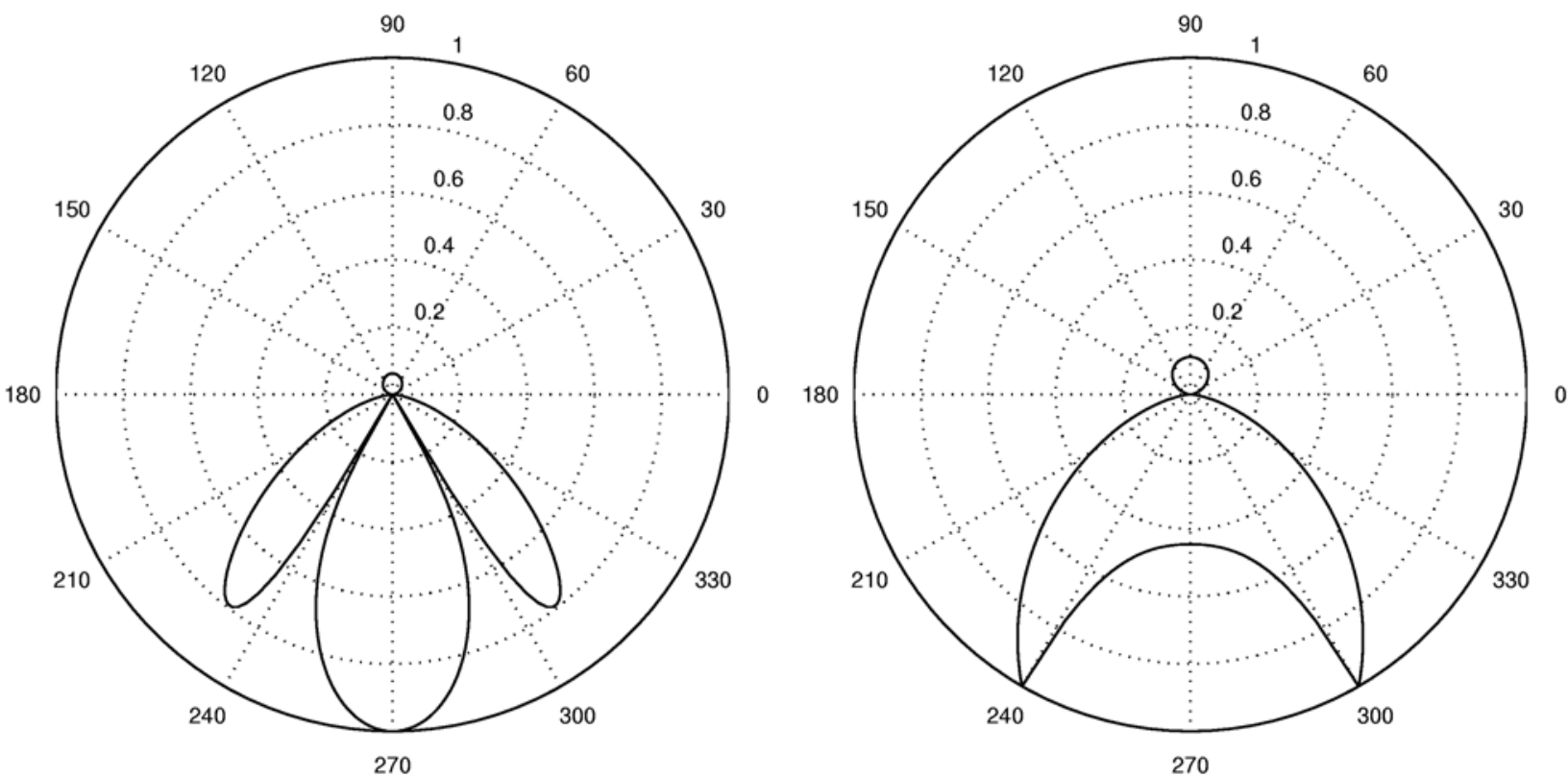

Figure 4. Radiation pattern of the electric monopole antennas represented in two planes, the vertical Eplane containing the antenna, the H-plane perpendicular to it.

signal analysis intended to demonstrate its capability to determine the direction of propagation of the reflected waves and thus the direction of the reflectors. This was done in a simplified geometry with 2 opposite electric monopoles on each side of the lander parallel to the $\mathrm{X}$ axis and for the simple case of a single smooth interface located at an average depth of $400 \mathrm{~m}$ and extending parallel to the $\mathrm{Y}$ axis. This interface is tilted from the horizontal at certain locations in order to allow the transmitted waves to reflect at some of these locations, two in the present case, in such a way that they can get back to the lander. A simple method, explained in more details in the companion paper [Ciarletti et al., 2003], has been used to perform an initial test and retrieve the directions of propagation of the detected waves. A schematic of the wave propagation and the comparison between the results from the signal analysis and the actual direction of the reflecting zone are shown in Figure 6. The agreement is excellent in spite of the nearly temporal coincidence of the returning waves.

\section{First Results from an Initial Field Test}

[22] We have performed an initial field test using a laboratory mock-up of the electronics and electric antennas.
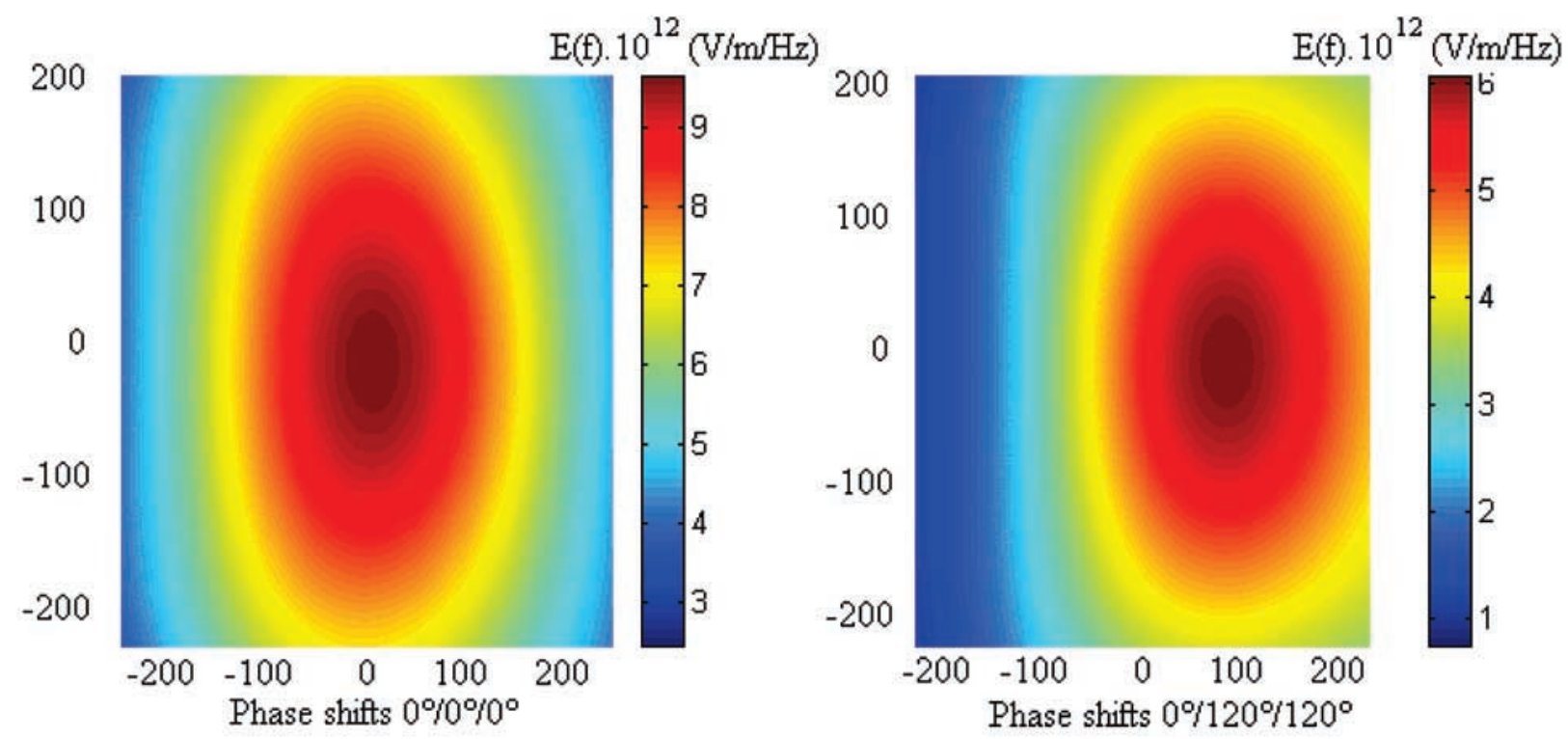

Figure 5. Illumination of the interface at $400 \mathrm{~m}$ for two different sets of phase shifts between the transmitting electric antennas. 


\section{Transmitter}

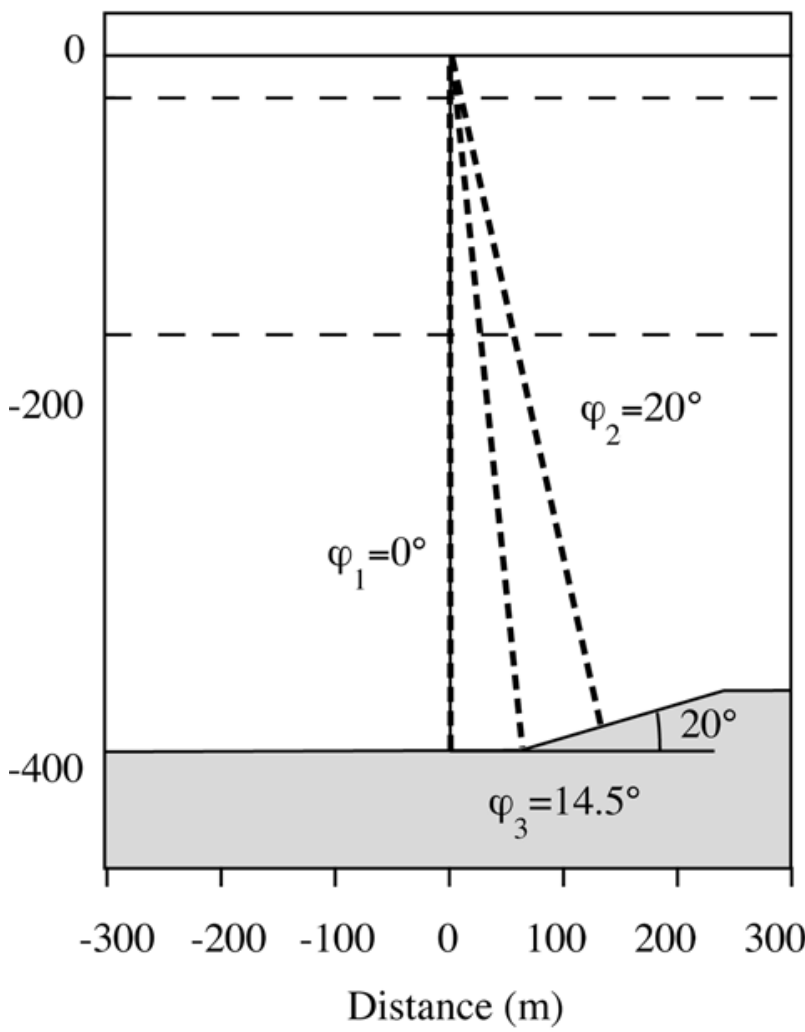

Figure 6. Schematic view of a nonplanar interface at 400 $\mathrm{m}$ and the corresponding results obtained for the direction of propagation of reflected waves.

This test had two main objectives. First to operate the radar with fully deployed electric antennas, which is not possible in the laboratory, in order to check its sensitivity in conditions as close as possible to those anticipated on Mars, then to estimate the practical blind zone of the radar. The GPR was operated at the end of November 2001 on Dune de Pyla, a big sand dune in the Landes forest close to the Atlantic Ocean coast. This dune which contains wet paleosoils acting as strong radar reflectors has often been used for ground-penetrating radar testing in the past [Barbin et al., 1995; Grandjean et al., 2001]. The radar was installed near the top of the dune at an altitude of about $85 \mathrm{~m}$ above the water table located at the base and underneath the dune. Echoes from this interface were detected with a moderate attenuation of about $50 \mathrm{~dB}$ showing that the effective blind zone of the radar was in practice on the order of $\sim 60 \mathrm{~m}$. In order to evaluate the sensitivity, and also to operate for the first time the radar in the "ionospheric" mode, we undertook to detect the base of the E-layer of the ionosphere using the $2 \mathrm{MHz}$ long pulse radar operation. Simultaneous observations from an ionospheric sounder located $200 \mathrm{~km}$ north of the radar site showed that the $2 \mathrm{MHz}$ critical frequency ionospheric layer was located at a virtual height of about $103 \mathrm{~km}$. Figure 7 shows the spectrum of the signal as detected by the electric antennas with a time delay of 670 $\mu \mathrm{s}$ and using $2^{17}$ coherent additions. For a comparison, the spectrum of the transmitted signal is indicated in the same figure: clearly the radar was able to detect the echo from the ionosphere in spite of a relatively high ambient radioelectric background due to industrial and HF radio-transmitter emissions. A more detailed report on the results of this initial field test is in preparation and will be published elsewhere.

\section{Conclusion}

[23] In the frame of the Netlander mission which aims at establishing on the surface of Mars a geophysical network of 4 stations, we have proposed to fly the GPR experiment, a ground-penetrating radar to explore the subsurface of the planet. Since the landers stay at fixed position the GPR is based on a new concept which allows us to obtain a 3-D image of the underground in the vicinity of the radar by determining not only the distance of the reflectors but also their direction. The objective is to reach a depth of about $2500 \mathrm{~m}$ since, according to generally agreed models, water reservoirs should exist under the form of ground ice at depths of a few hundreds of meters and under the form of liquid water below about 1 to $2 \mathrm{~km}$ at least at equatorial and low latitudes. The GPR will thus operate at a low frequency of 2 $\mathrm{MHz}$. The direction of the reflected waves will be performed by analyzing the electric and magnetic components of the wave field by methods which are derived from those previously used for the directional analysis of electromagnetic natural waves on board ionospheric satellites. We have given in this paper a short description of the instrument and some results from a numerical simulation to illustrate its performances. Preliminary results from an initial field test with a laboratory mock-up have shown that the blind zone and the sensitivity of the radar were in agreement with

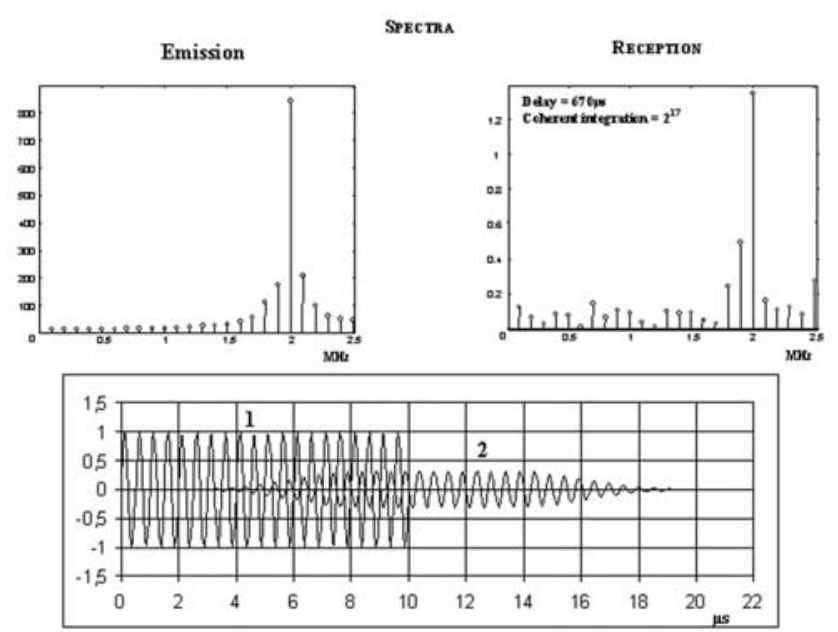

Figure 7. Initial results from an ionospheric sounding. Shown in the lower figure are the waveform of the transmitted signal (1) and the waveform of signal 2 obtained by sending signal 1 through the receiver filter (200 kHz bandwidth filter centered at $2 \mathrm{MHz}$ ). The upper figure on the left displays the spectrum of the centered $10 \mu \mathrm{s}$ of signal 2. The upper figure on the right shows the spectrum of the signal detected by the electric antennas 670 $\mu \mathrm{s}$ after emission and using $2^{17}$ coherent additions. 
expectation. It is anticipated that further field tests will be conducted in the near future, in particular, one in Egypt, close to the Siwa oasis, in a desert location where the subsurface has already been documented by drilling. In addition to its main mode of operation as a ground-penetrating radar, the GPR will be able to operate as an ionospheric sounder and will also be used in a passive mode as a riometer and to detect HF electromagnetic emissions from electrical discharges that are anticipated to occur due to intense impact charging of dust particles at times of dust storms.

[24] Acknowledgments. The present work has been undertaken under the auspices of CNES grants 793/CNES/99/7947 and 737/CNES/ 00/8261. We want to acknowledge the dedicated work of S. Bonaimé, F. Dolon and M. Rodriguez-Cassola during the development of the GPR and the initial field operations.

\section{References}

Annan, A. P., and J. L. Davis, Impulse radar sounding in permafrost, Radio Sci., 11, 383-394, 1976.

Arcone, S. A., Distortion of model subsurface radar pulses in complex dielectrics, Radio Sci., 16, 855-864, 1981.

Arcone, S. A., Numerical studies of the radiation patterns of resistively loaded dipoles, J. Appl. Geophys., 33, 39-52, 1995.

Baker, V. R., Water and the Martian landscape, Nature, 412(6843), 228 236, 2001.

Baker, V. R., R. G. Strom, V. C. Gulick, J. S. Kargel, G. Komatsu, and V. S. Kale, Ancient oceans and ice sheets and the hydrological cycle on Mars, Nature, 352, 589-594, 1991

Barbin, Y., F. Nicollin, W. Kofman, V. Zolotarev, and V. Glotov, Mars 96 GPR program, J. Appl. Geophys., 33, 27-37, 1995.

Barlow, N. G., J. M. Boyce, F. M. Costard, R. A. Craddock, J. B. Garvin, S. E. H. Skimoto, R. O. Kuzmin, D. J. Roddy, and L. A. Soderblom, Standardizing the nomenclature of Martian impact crater ejecta morphologies, J. Geophys. Res., 105(E11), 26,733-26,738, 2000.

Berthelier, J. J., et al., Measurements of the VLF electric and magnetic components of waves and DC electric field on board the AUREOL-3 spacecraft: The TBF-ONCH experiment, Ann. Geophys., 38, 643-667, 1982.

Berthelier, J. J., et al., The GPR experiment on NETLANDER, Planet. Space Sci., 48, 1161-1180, 2000.

Binder, A. B., and M. A. Lange, On the thermal history of a moon of fission origin, J. Geophys. Res., 85, 4872-4880, 1980.

Carr, M. H., Mars Global surveyor observations of Martian fretted terrain, J. Geophys. Res., 106(E10), 23,571-23,593, 2001.

Ciarletti, V., B. Martinat, A. Reineix, J.-J. Berthelier, and R. Ney, Numerical simulation of the operation of the GPR experiment on Netlander, J. Geophys., 108, doi:10.1029/2002JE001867, in press, 2003.

Clifford, S. M., A pore volume estimate of the Martian megaregolith based on a lunar analog, in Third International Colloquium on Mars, LPI Contrib. 441, pp. 46-48, Lunar and Planet. Inst., Houston, Tex., 1981.

Clifford, S. M., A model for the hydrologic and climatic behavior of water on Mars, J. Geophys. Res., 98(E6), 10,973-11,016, 1993.

Costard, F., The spatial distribution of volatiles in the Martian hydrolithosphere, Earth Moon Planets, 45, 265-290, 1989.

Costard, F., and J. Kargel, Outwash plains and thermokarst on Mars, Icarus, $114,93-112,1995$

Costard, F., F. Forget, N. Mangold, and J. P. Peulvast, Formation of recent Martian debris flows by melting of near-surface ground ice at high obliquity, Science, 295, 110-111, 2002.

Counil, J. L., F. Ferri, P. Lognonne, O. Marsal, F. Rocard, and R. Bonneville, The NETLANDER mission: A geophysical network aimed at investigating Mars atmosphere, sub-surface and deep interior, paper presented at Conference on the Geophysical Detection of Subsurface Water on Mars, Lunar and Planet. Inst., Houston, Tex., Aug. 2001.

Craddock, R. A., and T. A. Maxwell, Geomorphic evolution of the Martian highlands through ancient fluvial processes, J. Geophys. Res., 98, $3453-$ $3468,1993$.

Degauque, P., and J. P. Thery, Electromagnetic subsurface radar using the transient field radiated by a wire antenna, IEEE Trans. Geosci. Remote Sens., GE-24(6), 805-812, 1986

Engheta, N., and C. H. Papas, Radiation patterns of interfacial dipole antennas, Radio Sci., 17, 1557-1566, 1982.

Fanale, F. P., J. R. Salvail, A. P. Zent, and S. E. Postawko, Global distribution and migration of subsurface ice on Mars, Icarus, 67, 1-18, 1986.
Farrell, W. M., M. L. Kaiser, M. D. Desch, J. G. Houser, S. A. Cummer, D. M. Wilt, and G. A. Landis, Detecting electrical activity from Martian dust storms, J. Geophys. Res., 104, 3795-3801, 1999.

Forget, F., and R. T. Pierrehumbert, Warming early Mars with carbon dioxide clouds that scatter infrared radiation, Science, 278, 1273-1276, 1997.

Grandjean, G., P. Paillou, P. Dubois, T. August-Bernex, N. Baghdadi, and J. Achache, Subsurface structures detection by combining L-band polarimetric SAR and GPR data: Example of the Pyla Dune (France), IEEE Trans. Geosci. Remote Sens., 39(6), 1245-1258, 2001.

Habashy, T., and R. Mittra, On some inverse methods in electromagnetics, J. Electromagn. Waves Appl., 1(1), 25-58, 1987.

Haberle, R. M., Early Mars climate models, J. Geophys. Res., 103, 28,46728,479, 1998.

Heggy, E., Ph. Paillou, G. Ruffié, J.-M. Malézieux, F. Costard, and G. Grandjean, On water detection in the Martian subsurface using sounding radar, Icarus, 154(2), 244-257, 2001.

Heggy, E., Ph. Paillou, F. Costard, N. Mangold, G. Ruffié, F. Demantoux, G. Grandjean, and J.-M. Malézieux, Local geoelectrical models of the Martian subsurface for shallow groundwater detection using sounding radars, J. Geophys. Res., 108, doi:10.10292002JE001871, in press, 2002.

Hodges, R. R., Jr., The rate of loss of water from mars, Geophys. Res. Lett., 29(3), 1038, doi:10.1029/2001GL013853, 2002.

Hoffman, N., White Mars: A new model for Mars surface and atmosphere based on $\mathrm{CO}_{2}$, Icarus, 146, 326-343, 2000.

Hoolst, T. V., V. Dehant, and P. Defraigne, Chandler wobble and free core nutation for Mars, Planet. Space Sci., 48(12-14), 1145-1151, 2000.

Kanda, M., A relatively short cylindrical broadband antenna with tapered resistive loading for picosecond pulse measurements, IEEE Trans. Antennas Propag., AP-26, 439-447, 1978.

Lefeuvre, F., and C. Delannoy, Analysis of random electromagnetic wave field by a maximum entropy method, Ann. Telecomm, 34, 204-213, 1979.

Lefeuvre, F., M. Parrot, and C. Delannoy, Wave distribution function estimation of VLF electromagnetic waves, J. Geophys. Res., 86, 2359-2375, 1981.

Lefeuvre, F., J. L. Rauch, D. Lagoutte, J. J. Berthelier, and J. C. Cerisier, Propagation characteristics of dayside low-altitude hiss: Case studies, J. Geophys. Res., 97(7), 10,601-10,602, 1992.

Luhmann, J. G., R. E. Johnson, and M. H. G. Zhang, Evolutionary impact of sputtering of the Martian atmosphere by $\mathrm{O}^{+}$pick-up ions, Geophys. Res. Lett., 19, 2151-2154, 1992.

Malin, M. C., and K. S. Edgett, Evidence from recent ground water seepage and surface runoff on Mars, Science, 288, 2330-2335, 2000.

Mangold, N., and P. Allemand, Topographic analysis of features related to ice on Mars, Geophys. Res. Lett., 28(3), 407-410, 2001.

Mangold, N., P. Allemand, and P. G. Thomas, Wrinkle ridges of Mars: Structural analysis and evidence for shallow deformation controlled by ice-rich decollements, Planet. Space Sci., 46, 415-429, 1998.

Martinat, B., Etude electromagnétique du Ground Penatrating Radar de NETLANDER destiné au sondage du sous-sol martien Ph.D. thesis, 35-2001, Univ. of Limoges, Limoges, France, 2001.

Masson, P., M. H. Carr, F. Costard, R. Greeley, E. Hauber, and R. Jaumann, Geomophologic evidence for liquid water, Space Sci. Rev., 96, 385-416, 2001.

Means, J. D., On the use of the three-dimensional covariance matrix in analyzing the polarization properties of plane waves, J. Geophys. Res., $77,5551-5559,1972$.

Melnik, O., and M. Parrot, Electrostatic discharge in Martian dust storms, J. Geophys. Res., 103, 29,107-29,117, 1998.

Mellon, M. T., and R. J. Phillips, Recent gullies on Mars and the source of liquid water, J. Geophys. Res., 106, 23,165-23,179, 2001.

Mustard, J. F., C. D. Cooper, and M. K. Rifkin, Nature, 412, 411-414, 2001.

Ney, R., et al., The Ground Penetrating Radar of the Netlander mission, paper presented at Proceedings of the Ninth Conference on Ground Penetrating Radar: GPR 2002, Ground Probe Pty Ltd, Santa Barbara, Calif., April 2002.

Ogilvy, J. A., Theory of Wave Scattering From Random Rough Surfaces, chap. 5, pp. 118-133, A. Hilger, Philadelphia, Penn., 1991.

Sagan, C., and C. Chyba, The early faint sun paradox: Organic shielding of ultraviolet-labile greenhouse gases, Science, 276, 1217-1221, 1997.

Samson, J. C., Matrix and Stokes vector representation of detectors for polarized waveforms: Theory, with some applications to teleseismic waves, Geophys. J. R. Astron. Soc., 51, 583-603, 1977.

Siebert, N. M., and J. Kargel, Small-scale Martian polygonal terrain: Implications for liquid surface water, Geophys. Res. Lett., 28, 899-902, 2001.

Squyres, S. W., S. M. Clifford, R. O. Kuzmin, J. R. Zimbelman, and F. Costard, Volatiles in the Martian regolith, in Mars, edited by H. H. Kieffer et al., pp. 523-554, Univ. of Ariz. Press, Tucson, 1992. 
Thomas, P. G., and P. L. Masson, Martian fluidized crater distribution: Tectonic implications, Earth Moon Planets, 34, 169-176, 1995.

Ulaby, F. T., R. K. Moore, and A. K. Fung, Active microwave sensing of land, in Microwave Remote Sensing, vol. III, From Theory to Applications, chap. 21, pp. 1826-1827, Addison-Wesley-Longman, Reading, Mass., 1986.

Whitten, R. C., I. G. Popoff, and J. S. Sims, The ionosphere of Mars below $80 \mathrm{~km}$ altitude, Planet. Space Sci., 19, 243-250, 1971.

Winchester, C., and D. Rees, Numerical models of the Martian coupled thermosphere and ionosphere, Adv. Space Res., 15(4), 51-68, 1995.

Wright, D. L., S. M. Hodge, J. A. Bradley, T. P. Grover, and R. W. Jacobel, A digital low-frequency, surface-profiling ice-radar system, J. Glaciol., 36(122), 112-121, 1990.

$\mathrm{Wu}$, T. T., and R. W. P. King, The cylindrical antenna with non-reflecting resistive loading, IEEE Trans. Antennas Propag., AP-13(3), 369-373, 1965.

J. J. Berthelier, M. Hamelin, and R. Ney, Centre d'Etude des Environnements Terrestre et Planétaires/IPSL, 4 Avenue de Neptune, 94107 Saint-Maur Cedex, France. (ciarletti@cetp.ipsl.fr)

V. Ciarletti and B. Martinat, CETP/IPSL, 10/12 Avenue de l'Europe, 78140 Velizy, France. (ciarletti@cetp.ipsl.fr)
F. Costard, UMR 8616, Orsay-Terre, Université Paris-Sud, 91405 Orsay Cedex, France.

C. Duvanaud, LAII, Université de Poitiers, IUT, 4 Avenue de Varsovie, 16021 Angoulême Cedex, France.

G. Grandjean, Bureau de Recherches Géologiques et Minières, BP 6009 45060, Orléans, France.

W. Kofman, Laboratoire de Planétologie de Grenoble, Batiment D de la Physique, BP 53, 38041 Grenoble Cedex 09, France.

A. Nagy, College of Engineering, University of Michigan, Ann Arbor, MI 48109-2143, USA.

D. Nevejans, BIRA-Institut d'Aéronomie Spatiale de Belgique, Ringlaan 3, B-1180 Brussels, Belgium.

P. Paillou, Observatoire Astronomique de Bordeaux, BP 89, 33270 Floirac, France.

A. Reineix, Institut de Recherche en Communications Optiques et Microondes, Université de Limoges, 123 Avenue Albert Thomas, 87060 Limoges Cedex, France.

J. G. Trotignon, Laboratoire de Physique et Chimie de l'Environnement, 3 Avenue de la Recherche Scientifique, 45100 Orléans la Source, France.

M. Zamora, Institut de Physique de Globe de Paris, 4 place Jussieu, 75005 Paris, France. 